\title{
FORMAÇÃO INICIAL DE PROFESSORES DO ENSINO BÁSICO EM PORTUGAL E NO BRASIL: EXIGÊNCIAS LEGAIS E EXPECTATIVAS SOBRE O PROFISSIONAL DOCENTE
}

\author{
PROFESORES DE LA ESCUELA DE FORMACIÓN BÁSICA INICIAL EN \\ PORTUGAL Y BRASIL: LOS REQUISITOS LEGALES Y LAS EXPECTATIVAS \\ DE MAESTRO PROFESIONAL
}

\author{
PRIMARY TEACHER EDUCATION IN PORTUGAL AND BRAZIL: LEGAL \\ REQUIREMENTS AND EXPECTATIONS OVER THE TEACHING \\ PROFESSIONAL
}

\section{Jakeline Alencar Andrade ${ }^{1}$, Inês Nascimento ${ }^{2}$}

\section{RESUMO}

Este artigo discute a formação e a profissionalização docente a partir da compreensão de que as crescentes demandas sociais e de qualificação se acumulam sobre a profissão e delegam ao professor grandes responsabilidades a que se acrescentam as do seu próprio desenvolvimento profissional. O caráter interativo da profissão impõe ao professor dilemas e responsabilidades sobre a formação da moral, do caráter e da personalidade dos alunos. Buscamos identificar como essas demandas se refletem nas diretrizes de formação inicial dos professores a partir das exigências mínimas de qualificação, nos conteúdos da formação e no perfil do profissional a ser formado. Analisamos de forma comparativa as diretrizes relativas à formação inicial dos professores em Portugal (Lei de Bases do Sistema Educativo de 1986 e Decreto-Lei n. ${ }^{\circ}$ 43/2007) e no Brasil (Lei de Diretrizes e Bases da Educação de 1996 e Resolução n. ${ }^{\circ}$ 2/2015). Não obstante as diferenças identificáveis entre os dois países, as diretrizes trazem à tona uma formação, ora com ênfase no ensino de área e profissionalização do professor, como em Portugal, ora a compreensão das problemáticas sociais, como no Brasil. Percebe-se ainda que as competências definidas como desejáveis e expressas nessas diretrizes transcendem os currículos e assentam, sobretudo, na expectativa de que cada professor se disponha a um processo de desenvolvimento (pessoal e profissional) que promova o seu saber (fazer e estar) na profissão.

PALAVRAS-CHAVE: Formação docente. Práticas docentes. Perfil profissional.

\section{RESUMEN}

Este artículo discute la formación y la profesionalización docente a partir de la comprensión de que las crecientes demandas sociales y de calificación se acumulan sobre la profesión y deleguen al maestro grandes responsabilidades a las que se añaden las de su propio desarrollo profesional. El carácter interactivo de la profesión impone al profesor dilemas y responsabilidades sobre la formación de la moral, del carácter y de la personalidad de los alumnos. Buscamos identificar cómo estas demandas se reflejan en las directrices de formación inicial de los profesores a partir de las exigencias mínimas de

\footnotetext{
${ }^{1}$ Departamento de Fundamentos da Educação. Faculdade de Educação. Universidade Federal do Ceará.

${ }^{2}$ Universidade do Porto. Portugal.
} 


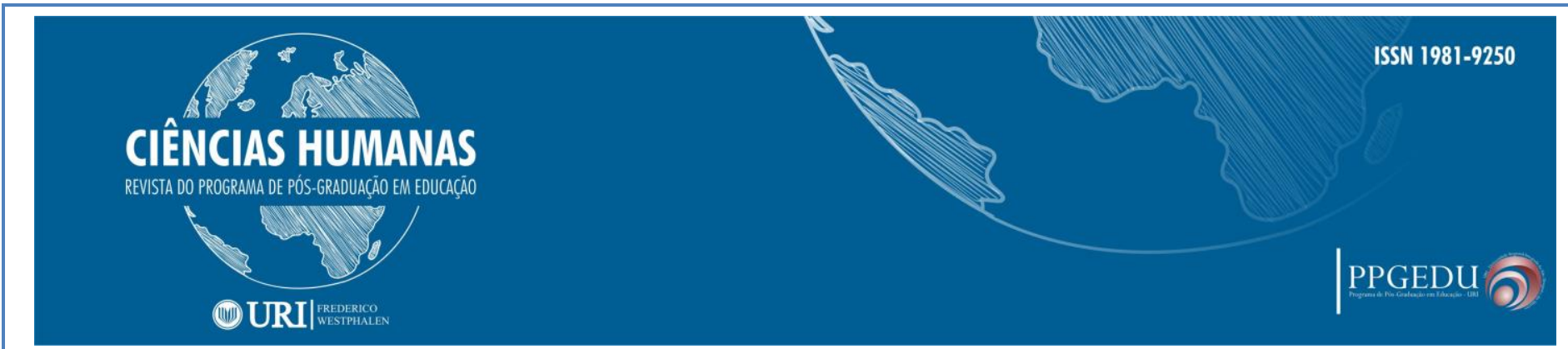

cualificación, en los contenidos de la formación y en el perfil del profesional a ser formado. Analizada de manera comparativa las directrices relativas a la formación inicial de los profesores en Portugal (Ley Orgánica de Educación de 1986 y el Decreto Ley 43/2007) y Brasil (Ley de Directrices y Bases de la Educación de 1996 y la Resolución No. 2/2015). A pesar de las diferencias identificadas entre los dos países, las directrices llevar a la formación de la luz, a veces con énfasis en el área de la educación y profesional de los maestros, como en Portugal, ahora la comprensión de los problemas sociales, como Brasil. Se percibe además que las competencias definidas como deseables y expresadas en esas directrices trascienden los currículos y se basan, sobre todo, en la expectativa de que cada profesor se disponga a un proceso de desarrollo (personal y profesional) que promueva su saber (hacer y estar) en la profesión.

PALABRAS CLAVE: Formación docente. Prácticas docentes. Perfil profesional.

\begin{abstract}
This article discusses teachers education and professionalism by the understanding that increasing of social demands as the critical need for well-qualified teachers have delegate great responsibilities to which are added from those of their own professional development. The interactive character of the profession imposes to the teachers dilemmas and responsibilities for the moral development, the character, and the personality of the students. We seek to identify how these demands are reflected in the initial formation guidelines based on the minimum qualification requirements, the programs and the professional profile to be formed. We analyzed in a comparative way the guidelines regarding the initial teachers education in Portugal (Basic Education Act of 1986 and Decree-Law no. 43/2007) and in Brazil (Education and Policy Basis of 1996 and Resolution n 2/2015). Notwithstanding the identifiable differences between the two countries, the guidelines bring up: the emphasis on teaching area and teacher professionalization, in Portugal; and the understanding of social problems, in Brazil. It is also noticed that the competencies defined as desirable and expressed in these guidelines transcend the curricula and are based, above all, on the expectation that each teacher is willing to a process of development (personal and professional) that promotes their knowledge (to do and to be) in the profession.
\end{abstract}

KEYWORDS: Teacher education. Teaching practices. Professional Profile.

\title{
CONSIDERAÇÕES INICIAIS SOBRE A FORMAÇÃO DE PROFESSORES
}

A formação dos professores assume grande importância em decorrência do processo de escolarização que marcou a primeira metade do século XX. Desde então, a formação docente se incumbe tanto de demandas sociais relacionadas às expectativas que a atividade escolar representa nos diferentes estratos sociais, como das competências que se querem nos professores, responsáveis pela educação das próximas gerações. Ao longo da história da formação e profissionalização dos professores, nos deparamos com diretrizes que buscam responder não apenas a crescente universalização da escolarização no mundo, mas a estas crescentes demandas sociais.

As primeiras iniciativas de formação dos professores são, portanto, associadas às concepções de ensino escolar vigentes. Se o ensino era transmissão de conhecimento, ensinar era a arte de repassar o conhecimento do professor para o aluno, segundo Moreira (2012, p. 1139), “a lógica subjacente é que o bom professor precisa, antes de 


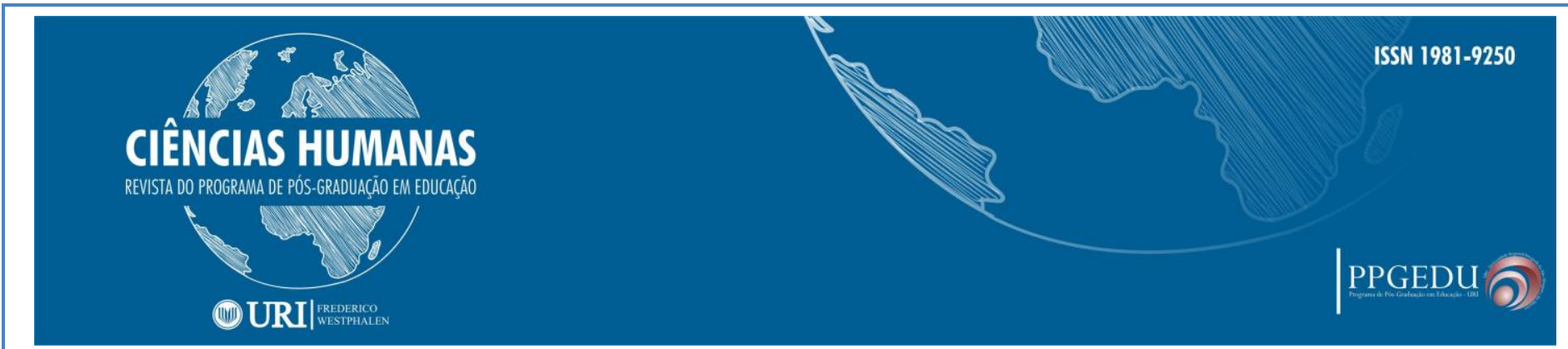

tudo, deter o conhecimento. Mas isso não basta, há professores que sabem muito, mas não sabem transmitir. É preciso, também, saber ensinar".

De acordo com Libâneo (2004), se há mudanças sobre as concepções de aprendizagem, estas incidem sobre as formas de ensinar. Devido à subordinação das práticas de ensino à aprendizagem, o programa de formação dos professores deve corresponder ao que se espera da aprendizagem dos alunos. A sociedade da informação e do conhecimento, dos meios digitais e das relações sociais mediadas por tecnologias, requer não apenas o papel ativo dos sujeitos na aprendizagem, mas demandam o desenvolvimento de habilidades de pensamento e de competências cognitivas. O que converge com a indicação de que a escola e os professores pautar-se-ão pelos pilares da educação ao longo da vida, ensinando os alunos a aprender a pensar, a se relacionar e a compreender a si e ao mundo (UNESCO, 2010).

Compreendemos que a tarefa dos professores tem se complexificado ao longo do próprio processo de escolarização, segundo Tardif e Lessard (2005) se a tarefa primordial do professor é o ensino, ela engloba aspectos como a transmissão e a socialização, a aprendizagem e a disciplina, o conteúdo cognitivo e o princípio pedagógico; além das vivências escolares do cotidiano que impõem ao professor responsabilidades para com a formação da moral, do caráter e da personalidade dos alunos.

Ao nos propormos a identificar as estratégias dos professores para se desenvolverem ao longo de sua prática educativa, debruçamo-nos sobre a formação dos professores na atualidade. Neste texto, analisamos a legislação sobre a formação dos professores em Portugal e no Brasil, considerando, as Leis de Bases da Educação e as diretrizes de formação dos professores da Educação Básica nos dois países. Elaboramos um quadro comparativo sobre as exigências mínimas de formação para o exercício da docência; sobre os conteúdos específicos e o perfil profissional esperado dos egressos das formações iniciais e continuadas. Discutiremos também, a contribuição desta formação para atender as demandas sociais que recaem sobre a profissão.

A título de exemplo, a exigência da formação em nível superior para o exercício da docência, em Portugal e no Brasil, ocorrem em momentos distintos, mas acarretam aligeiramento das formações para cumprimento de metas educacionais ou agendas externas, muitas vezes distanciadas da realidade da carreira docente e das escolas. Do mesmo modo, o perfil do profissional do egresso da formação inicial, nos dois países, reflete demandas sociais, como o domínio técnico-científico atualizado e o pensamento inclusivo, contudo, ao mesmo tempo, delega ao professor a responsabilidade pelo seu percurso e aprendizagem, remetendo-o ao processo de formação "ao longo da vida".

\section{AS EXIGÊNCIAS MÍNIMAS DE FORMAÇÃO DOS PROFESSORES}


Segundo a análise de Nóvoa (1992), se ao longo de todo o século XIX a imagem do professor se consolidou em referências cruzadas entre o magistério docente e o sacerdócio, tal entremeio impregnou a história contemporânea dos professores: "não devem saber de mais, nem de menos; não se devem misturar com o povo, nem com a burguesia; não devem ser pobres, nem ricos; não são (bem) funcionários públicos, nem profissionais liberais; etc".

O fato é que a formação dos professores sempre fez parte de demandas sociais e políticas, por isso a profissão se produziu entre projetos muitas vezes conflitantes e contraditórios. Segundo o autor: "Mais do que um lugar de aquisição de técnicas e de conhecimentos, a formação de professores é o momento chave da socialização e da configuração profissional” (NÓVOA, 1992, p. 13-33). Pois, a análise das reformas educacionais e das diretrizes de formação nos mostram que, historicamente, a percepção desta realidade tem levado a formação dos professores a reboque de projetos políticos que não condizem, necessariamente, com a qualidade da profissionalização do professor. E ainda que o autor verse sobre a realidade portuguesa, a afirmação não soa estranha às políticas de formação de professores no Brasil.

Entretanto, em Portugal, os professores desempenham um papel crucial na construção do país contemporâneo e, por isso mesmo, sofreram continuamente com mudanças no posicionamento do Estado ao longo das políticas de formação de professores que marcaram a segunda metade do século XIX e primeira do século XX (NÓVOA, 1992). Os professores sempre estiveram, desde a sua formação ao desenvolvimento da carreira, submetidos a um controle muito próximo do Estado. Assim, a formação dos professores foi sujeita à redução e controle pela baixa exigência para o ingresso nos programas de formação e pela "instauração de práticas de controlo moral e ideológico, tanto na formação de base, como no estágio e na avaliação dos exames de estado" (NÓVOA, 1992, p. 13-33).

Para o autor, a formação docente vem regressar ao primeiro plano em Portugal somente na década de 1960, quando o país surge em último lugar nas estatísticas europeias; a nova realidade econômica e social do país exige soluções educacionais agora observadas e influenciadas externamente. A presença da Organização para a Cooperação e Desenvolvimento Econômico (OCDE) contribuiu para acentuar "o papel da educação na formação do capital humano e para criar uma escola de planejamento do ensino", de modo que as décadas seguintes foram marcadas pela formação inicial dos professores (1970); pela profissionalização em serviço dos professores (1980); e pela formação contínua de professores (1990) (NÓVOA, 1992).

Por sua vez, a formação dos professores no Brasil torna-se uma preocupação quando do movimento de instrução popular que ganhou força com a independência. E, 


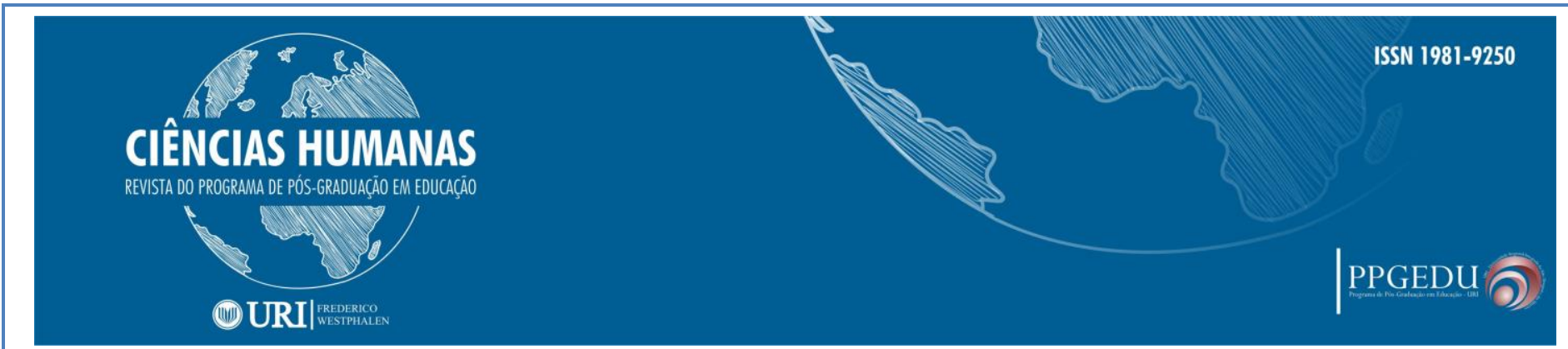

ao examinar as questões pedagógicas e a formação dos professores articuladas às transformações que se processaram na sociedade brasileira ao longo dos últimos dois séculos, Saviani (2009) distingue um primeiro período (1827-1890) como "Ensaios intermitentes de formação de professores", marcado pela inexistência de uma diretriz específica ou formação oficial de professores, onde prevalecia o ensino mútuo. Para o autor, o marco inicial da formação profissional dos professores no Brasil pode ser identificado como o "Estabelecimento e expansão do padrão das Escolas Normais (1890-1932)".

Desse período até a atualidade, houve movimentos de implementação e da Organização dos Institutos de Educação (1932- 1939) até a implantação dos Cursos de Pedagogia e de Licenciatura (1939) onde prevaleceu o esquema " $3+1$ " para a formação de professores das diversas áreas do conhecimento escolar. Apesar do visível movimento de profissionalização a nível superior dos professores, a década de 19962006 é marcada pelo advento dos Institutos Superiores de Educação, Escolas Normais Superiores e o novo perfil do Curso de Pedagogia; tal dicotomia foi provocada pela ambiguidade da Lei de Diretrizes e Bases da Educação de 1996 (LDB), que se distanciou das expectativas dos movimentos de professores e da sociedade civil ao preconizar a valorização do magistério e a qualidade da formação dos professores em nível superior e, ao mesmo tempo, admitir a formação em nível secundário, nas escolas normais ou institutos superiores de educação. $\mathrm{O}$ que significaria uma volta ao passado com formações mais técnicas, aligeiradas e a baixo custo.

Ao analisarmos, paralelamente, as leis de bases da educação em Portugal (1986) e no Brasil (1996), é possível perceber a convergência no que se refere às exigências mínimas da profissão: entre as décadas de 1980/1990 há uma preocupação crescente com a profissionalização do professor, advindas das políticas externas que demandam aos dois países um maior investimento na qualidade da educação e, consequentemente, na formação dos professores. O quadro a seguir mostra a formação mínima exigida em cada um dos países:

QUADRO 1 - Formação Mínima para o exercício da docência na Educação Infantil e $1 .^{\text {os }}$ ciclos/anos da Educação Básica/Ensino Fundamental

\begin{tabular}{|l|l|}
\hline PORTUGAL (1986) & BRASIL (1996) \\
\hline $\begin{array}{l}\text { Em cursos superiores organizados de acordo o } \\
\text { respectivo nível de educação e ensino. }\end{array}$ & $\begin{array}{l}\text { Em nível superior, em curso de } \\
\text { licenciatura plena. }\end{array}$ \\
\hline
\end{tabular}

3 O esquema " $3+1$ " se refere ao bacharelado, formação concentrada em conteúdos de área específica de conhecimento, com duração de 3 anos e mais 1 ano de formação pedagógica para obtenção da licenciatura.

\begin{tabular}{l|c|c|c|}
\hline Rev. Ciências Humanas & Frederico Westphalen, RS & Pg. 143 - 157 & mai./ago. 2018 \\
\hline
\end{tabular}

\begin{tabular}{l|l} 
Recebido em: 03/10/2018 & Aceito em: 19/11/2018
\end{tabular}




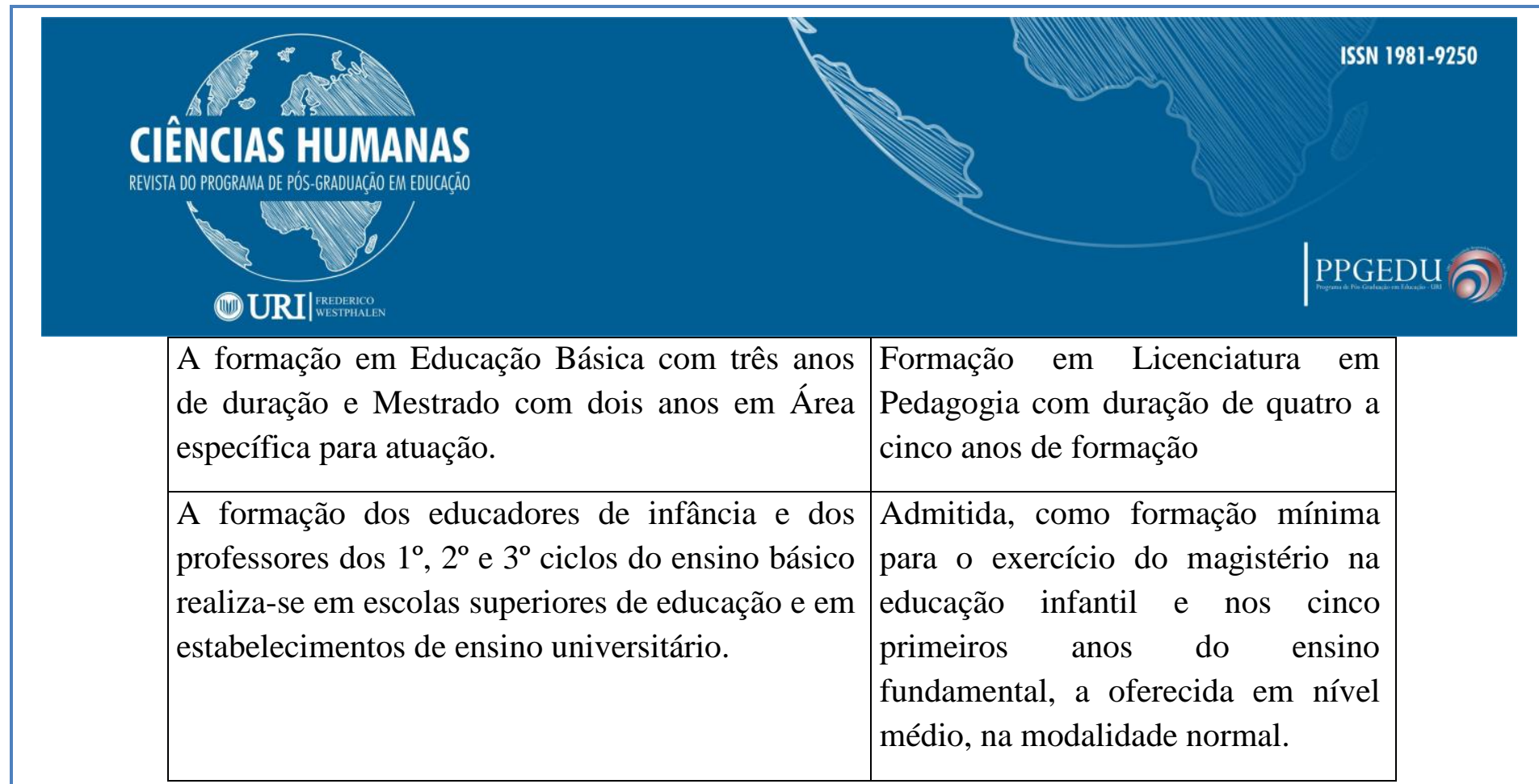

Fonte: Autoras; levantamento dos dados; pesquisa documental.

Os dois países exigem nível superior de educação como formação mínima para o exercício da docência. No entanto, há diferenças significativas na estruturação da formação docente em nível superior.

Em Portugal, a formação inicial de nível superior é exigida para o exercício do magistério desde a Educação Infantil ao Secundário, no entanto, apenas o mestrado (2. ${ }^{\circ}$ ciclo) habilita para a docência nos diferentes níveis e áreas de ensino. Enquanto a licenciatura em Educação Básica (1. ${ }^{\circ}$ ciclo) habilita o diplomado a integrar equipes multidisciplinares, com funções educativas de apoio e cooperação dentro e fora do sistema educativo. Deste modo, ao professor de educação infantil e do $1 .^{\circ}$ e $2{ }^{\circ}$ ciclos da educação básica são exigidos no mínimo 6.600 horas de formação, compreendidas entre a licenciatura (180 créditos $^{4}$ ou 4950 horas, aproximadamente) e o mestrado (60 créditos ou 1650 horas, aproximadamente). A formação inicial acontece majoritariamente nos Institutos Superiores de Educação e nas Escolas Superiores de Educação, públicas e privadas, haja vista que das 30 instituições a formar professores, apenas sete são universidades 5 .

Em estudo sobre a formação inicial de docentes, Almeida e Faria (Conselho Nacional de Educação, 2015, p. 21-85) analisaram a base de dados do Sistema de Informação do Ministério da Educação (MISI) da Direção-Geral de Estatísticas da Educação e Ciência (DGEEC), referente ao ano letivo de 2012/2013 e demonstraram "um aumento exponencial de docentes portugueses com licenciaturas e mestrados, sobretudo a partir de 1986, acompanhando, assim, o contexto internacional da universitarização dos estudos" (p. 27). As autoras destacaram ainda, que a grande incidência de professores com Magistério Primário pode ser explicada pela alta

$4 \quad \mathrm{Na}$ europa, o Acordo de Bolonha implementou as ECTS (European Credits Transfer System) que facilita e garante o aproveitamento de estudos entre os países-membro. Cada ECTS equivale a um intervalo entre 25 e 30 horas de atividades letivas.

5 Dados disponibilizados pela Direção Geral do Ensino Superior/Portugal (DGES).

\begin{tabular}{l|c|c|c|}
\hline Rev. Ciências Humanas & Frederico Westphalen, RS & Pg. 143 - 157 & mai./ago. 2018 \\
\hline
\end{tabular}

\begin{tabular}{l|l} 
Recebido em: 03/10/2018 & Aceito em: 19/11/2018
\end{tabular}




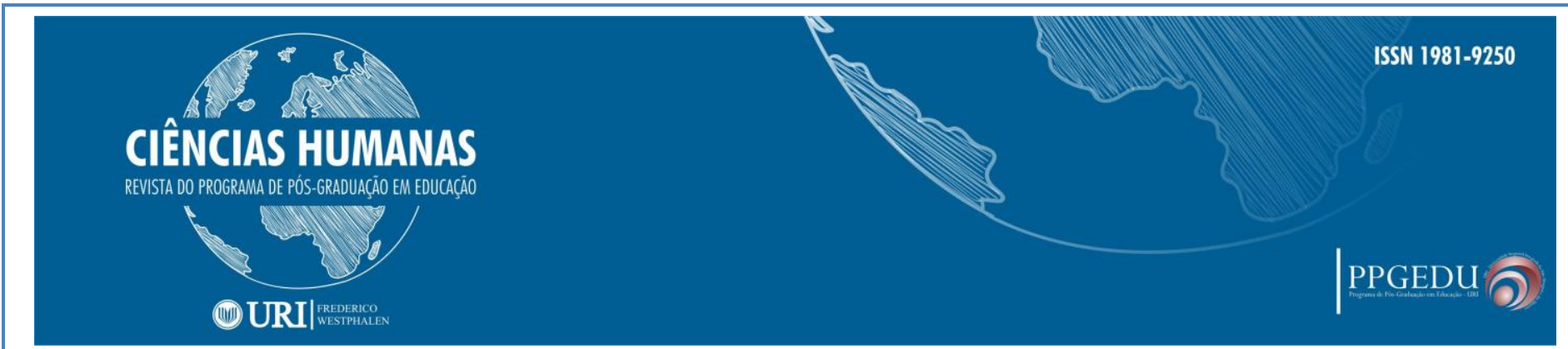

concentração da faixa etária dos docentes entre 41 e 60 anos (mais de 70\%), que concluíram sua formação antes da Lei de Bases de 1986 ou, mesmo, do Processo de Bolonha, que estruturou o ensino superior em três ciclos e, consequentemente, a habilitação profissional para a docência passou a ser o mestrado.

No Brasil, a Lei de Diretrizes e Bases da Educação Nacional (LDB) de 1996 estabelece a formação de nível superior nos cursos de licenciatura como habilitação mínima para o magistério. A incoerência da Lei residia principalmente em dois pontos: (1) admitir em seu texto permanente a formação mínima em nível médio (secundário) para os professores da Educação Infantil e primeiros anos do Ensino Fundamental em escolas normais ou institutos de educação superior e (2) estabelecer uma meta vinculada ao Plano Nacional de Educação (1997-2007) em que somente seriam admitidos professores habilitados em nível superior ou formados por treinamento em serviço a contar dez anos da promulgação da LDB. Em resumo, a lei é dúbia e levou a uma década de formações aligeiradas, criação e extinção de Escolas Normais Superiores e Institutos Superiores de Educação, assim como mudanças curriculares nos cursos de Pedagogia que, naquele momento lutavam por uma identidade entre a formação do especialista em educação ou do professor da educação infantil e das séries iniciais do Ensino Fundamental. Segundo Saviani (2009, p. 148), “a LDB sinalizou para uma política educacional tendente a efetuar um nivelamento por baixo: os institutos superiores de educação emergem como instituições de nível superior de segunda categoria, provendo uma formação mais aligeirada, mais barata, por meio de cursos de curta duração".

Apesar da polêmica, a Resolução n. ${ }^{\circ} 01$ de 2006 estabeleceu as Diretrizes para o curso de pedagogia, consolidando-o como a habilitação para o magistério da Educação Infantil e Séries Iniciais do Ensino Fundamental. Enquanto a Resolução n. ${ }^{\circ} 02$ de 2015, estabelecia as diretrizes de formação inicial e continuada dos professores da Educação Básica como um todo, ampliando a carga horária mínima de todos os cursos de licenciaturas de 2800 para 3200 horas, além de estabelecer uma proporção maior de conteúdos pedagógicos e práticos durante a formação, o que, em tese, procura corrigir uma lacuna histórica no que se refere à profissionalização do professor nos cursos de licenciatura brasileiros que, em sua maioria, caracterizam-se pela ausência de uma formação voltada para a docência ${ }^{6}$.

Segundo o Instituto Nacional de Estudos e Pesquisas Educacionais Anísio Teixeira (INEP, 2017), o Brasil tem 2,2 milhões de professores atuando na Educação Básica (Educação Infantil até o Ensino Médio/Secundário) da rede de ensino pública e

6

Cabe ressaltar que a resolução n. ${ }^{\circ}$ 02/2015 está em implementação, o prazo para adequação dos cursos de licenciatura era, inicialmente de dois anos, mas houve pelos menos duas prorrogações oficiais a pedido do próprio Ministério da Educação. 


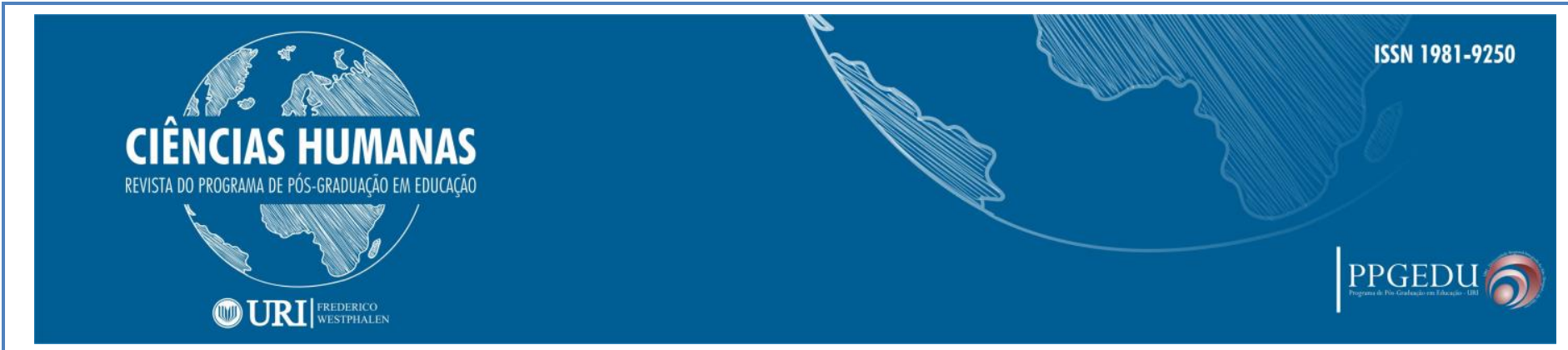

privada. Em 2017, 67\% dos professores da Educação Infantil e 72\% dos professores das séries iniciais do ensino fundamental possuíam formação em nível superior. Esses mesmos indicadores mostravam 53\% e 66\%, respectivamente, em 2011. Quanto às disciplinas, 55,7\% eram ministradas por professores com formação em licenciatura na mesma área da disciplina. Em 2013, o mesmo Indicador era de 51,2\% professores com formação adequada ${ }^{7}$. Percebe-se, através destes indicadores, que o Brasil vem avançando na formação dos professores, quer na proporção de professores com nível superior, quer na adequação dessa formação as disciplinas ministradas.

Assim, Portugal e Brasil apresentam disparidades na exigência de formação mínima aos professores de Educação Infantil e séries iniciais, tanto no tempo, com uma diferença exata de uma década (legislação de ensino em 1986 e 1996), quanto em grau, mestrado e nível médio/secundário, respectivamente, como o grau mínimo exigido para habilitação ao magistério. No entanto, ambos os países avançam na formação e exigências à docência, consolidando um aumento significativo do número de professores com nível superior e estabelecendo este nível como o mínimo para a educação das crianças na escola.

Tais exigências se tornam mais evidentes nas diretrizes que estabelecem os princípios e o perfil profissional da formação de professores conduzida pelos dois países.

\section{O CONTEÚDO DA FORMAÇÃO}

Apesar da exigência mínima de nível superior representar uma conquista de valorização da profissão docente, a formação está cada vez mais sob a tutela do Estado. É nesse sentido que os princípios da Base Nacional Comum para a formação dos professores são regulamentados, tanto em Portugal (Decreto-Lei n. ${ }^{\circ}$ 240/2001, DecretoLei n. ${ }^{\circ}$ 241/2001 e Decreto-Lei n. ${ }^{\circ}$ 43/2007), como no Brasil (Resolução n. ${ }^{\circ}$ 01/2006 e Resolução n. ${ }^{\circ}$ 2/2015), por força de leis que estabelecem nacionalmente as diretrizes da formação docente.

Em Portugal, a formação inicial se quer estreitamente ligada aos "perfis específicos de desempenho profissional do educador" de modo que a "habilitação" expressa nas diretrizes da formação procura se aproximar do que se espera dos docentes no início do seu exercício profissional, assim como considera a "necessidade de adaptação do professor às mudanças decorrentes das transformações emergentes na sociedade, na escola e no papel do professor, da evolução científica e tecnológica e dos contributos relevantes da investigação educacional" (PORTUGAL, 2007, p. 1321).

$7 \quad$ Os dados informados foram consultados a partir dos microdados e notas técnicas divulgadas anualmente pelo INEP. 


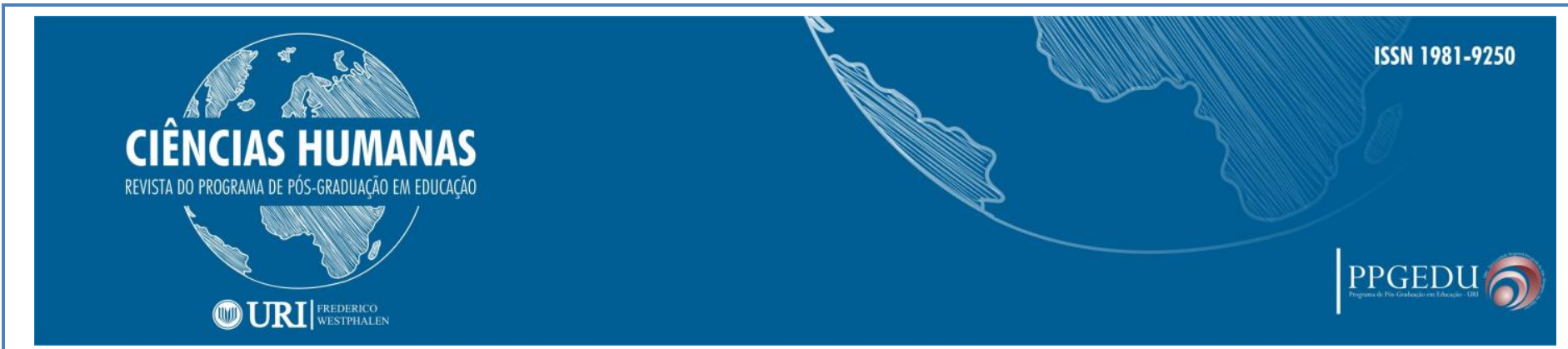

Deste modo, o direcionamento da formação é pautado pelos princípios do conhecimento disciplinar, da fundamentação da prática de ensino, da investigação e da iniciação à prática profissional. Como componentes da formação, estabelece os tópicos de educação geral, as didáticas específicas, a iniciação à prática profissional, a formação cultural, social e ética, a formação em metodologias de investigação educacional e a formação na área de docência. A formação dos professores em Portugal destaca-se, portanto, sobre a prática de ensino e o conhecimento educacional da área disciplinar a ser lecionada.

No Brasil, a Resolução n. ${ }^{\circ}$ 02/2015 estabelece como princípios da formação inicial e continuada dos professores uma sólida formação teórica e interdisciplinar, a unidade teoria-prática, o trabalho coletivo e interdisciplinar, o compromisso social e valorização do profissional da educação, a gestão democrática, assim como, a avaliação e a regulação dos cursos de formação docente. Os componentes da formação estão elencados de acordo com três núcleos: (1) estudos de formação geral que envolvem desde os conhecimentos pedagógicos das diferentes áreas disciplinares até a compreensão social e ética da profissão; (2) de aprofundamento e diversificação de estudos das áreas de atuação profissional, "incluindo os conteúdos específicos e pedagógicos, priorizadas pelo projeto pedagógico das instituições, em sintonia com os sistemas de ensino" (BRASIL, 2015, p. 10) e, (3) de estudos integradores com vistas ao enriquecimento curricular através de estágios, atividades extras, pesquisas, extensão, projetos e intercâmbio.

A despeito das diretrizes que regulamentam a formação e a profissão dos professores em Portugal e no Brasil, observa-se uma clara tendência para a ampliação dessa formação no sentido de aproximar os futuros professores das necessidades e da realidade educacional de cada país. Os professores cada vez mais são chamados a responder pela educação de uma sociedade complexa, com suas desigualdades sociais e em constante transformação. As diretrizes trazem à tona a demanda social por professores bem preparados tecnicamente, seja pelo domínio de sua área de conhecimento, seja, principalmente, pela compreensão da dimensão social da profissão e da educação e de seus desafios. Tais demandas extrapolam o currículo da formação inicial e preveem a construção de um perfil profissional, que exige continuidade seja do desenvolvimento dessa formação ao longo do tempo, seja da própria pessoa do professor. É o que poderemos verificar no perfil do formando ou do egresso das formações de professores expressas nas diretrizes de Portugal e do Brasil, ainda que as preocupações nelas presentes sejam diferenciadas.

\section{O PERFIL DO PROFISSIONAL EGRESSO DA FORMAÇÃO INICIAL}




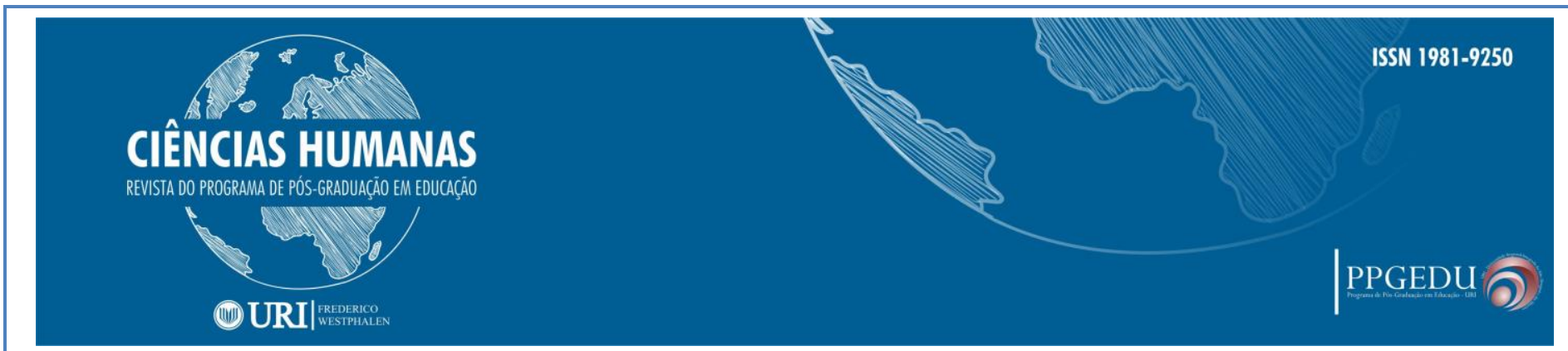

O quadro a seguir resume o perfil do profissional expresso nas diretrizes de formação dos professores em Portugal e no Brasil. Apesar das ênfases que veremos a seguir, o perfil evidencia expectativas sobre a profissão que transcendem a função específica de ensinar, ou mesmo os limites de uma formação inicial, e evocam, de certo modo, a "missão" e o comprometimento pessoal envolvidos na prática docente.

QUADRO 2 - Perfil do profissional egresso da formação inicial

\begin{tabular}{|l|l|} 
Portugal & Brasil \\
\hline $\begin{array}{l}\text { II - Dimensão profissional, social e ética; } \\
\text { da aprendizagem; }\end{array}$ & $\begin{array}{l}\text { I- informações e habilidades compostas pela } \\
\text { pluralidade de conhecimentos teóricos e } \\
\text { práticos; }\end{array}$ \\
$\begin{array}{l}\text { IV - Dimensão de participação na escola e de de desenvolvimento do ensino } \\
\text { relação com a comunidade; }\end{array}$ & $\begin{array}{l}\text { II- percurso formativo fundamentado em } \\
\text { princípios de interdisciplinaridade, } \\
\text { contextualização, democratização, pertinência e } \\
\text { relevância social, ética e sensibilidade afetiva e } \\
\text { V - Dimensãtica; }\end{array}$ \\
ao longo da vida. & $\begin{array}{l}\text { III - consolidação dos princípios formativos no } \\
\text { exercício profissional. }\end{array}$ \\
\hline
\end{tabular}

Fonte: Autoras; levantamento dos dados; pesquisa documental.

Em Portugal, o perfil requer um profissional sensível às demandas sociais advindas do contexto escolar, às problemáticas de aprendizagem e que contextualize o ensino de acordo com as necessidades do aluno. O professor deve também envolver-se nas atividades de gestão, participando ativamente das políticas educacionais e do projeto escolar, além de prezar pelo rigor científico e metodológico de acordo com o currículo estabelecido. Há uma preocupação com a formação de uma base de conhecimento científico na área de ensino que aparece com ênfase em todas as quatro dimensões do perfil, onde destacamos algumas expressões no Decreto-Lei n. ${ }^{\circ}$ 240/2001, que denotam a tônica no ensino e no conhecimento científico, ou seja, na especificidade escolar da profissão: "promove aprendizagens curriculares", exerce a "a função específica de ensinar", está "enquadrado em orientações de política educativa" e promove aprendizagens no âmbito de um currículo" com "rigor científico e metodológico, conhecimentos das áreas que o fundamentam" (PORTUGAL, 2001, p. 5570-2).

O professor em Portugal, também deve "garantir o bem-estar dos alunos e o desenvolvimento de todas as componentes da sua identidade individual e cultural", 


\section{CIÊNCIAS HUMANAS}

REVISTA DO PROGRAMA DE PÓS-GRADUAÇ̄OA EM EDUCAÇ̄̃O

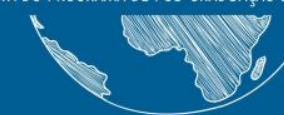

\section{(1) URI|}

assim como manifestar "equilíbrio emocional, nas várias circunstâncias da sua actividade profissional" e assumir "a dimensão cívica e formativa das suas funções, com as inerentes exigências éticas e deontológicas que lhe estão associadas". A despeito do que são ou seriam essas funções associadas, pois exerce a "função específica de ensinar", o professor também deve "incorporar a sua formação como elemento constitutivo da prática profissional", enquanto "reflecte sobre aspectos éticos e deontológicos inerentes à profissão, avaliando os efeitos das decisões tomadas" e "desenvolve competências pessoais, sociais e profissionais, numa perspectiva de formação ao longo da vida" (idem).

No Brasil, veremos que as expectativas sobre o perfil profissional se assemelham a Portugal e remetem também ao professor reflexivo, comprometido socialmente com sua função e partícipe da gestão da escola. No entanto, ainda que a habilitação seja específica para a docência como em Portugal, o perfil desse profissional egresso dos cursos de formação no Brasil indica que este "deverá possuir um repertório de informações e habilidades composto pela pluralidade de conhecimentos teóricos e práticos" que lhe possam permitir a atuação como (1) especialista em educação, que tem o "o conhecimento da instituição educativa como organização complexa na função de promover a educação para e na cidadania', do (2) professor-pesquisador, que se utiliza da "pesquisa, a análise e a aplicação dos resultados de investigações de interesse da área educacional e específica" e a de (3) professor de sala de aula (efetivamente), com a "atuação profissional no ensino, na gestão de processos educativos e na organização e gestão de instituições de educação básica" (BRASIL, 2015, p. 7). Em suma, habilita-se o professor a partir de um referencial em "informações e habilidades", mas espera-se uma atuação tripla que exige competências amplas cuja consolidação "virá do seu exercício profissional" e não desta mesma formação.

Destacamos ainda, na Resolução n. ${ }^{\circ} 02$ de 2015, que se espera desse professor que atue com "ética e compromisso com vista à construção de uma sociedade justa, equânime, igualitária", que compreenda "o seu papel na formação dos estudantes da educação básica a partir de concepção ampla e contextualizada de ensino e processos de aprendizagem e desenvolvimento"; além de "dominar os conteúdos específicos e pedagógicos e as abordagens teórico-metodológicas do seu ensino", e, "facilitar relações de cooperação entre a instituição educativa, a família e a comunidade" (BRASIL, 2015, p. 7-8). Tudo isso, assumindo uma postura investigativa, integrativa e propositiva diante dos problemas socioculturais e educacionais, de modo a contribuir para a inclusão de todos.

Não é de se estranhar que tanto a legislação portuguesa, quanto a brasileira, advoguem a formação ao longo da vida como percurso profissional e também, como resultado da formação do professor. Se a profissionalização do professor foi impulsionada pela elevação do nível de qualificação e das exigências do perfil, esta 


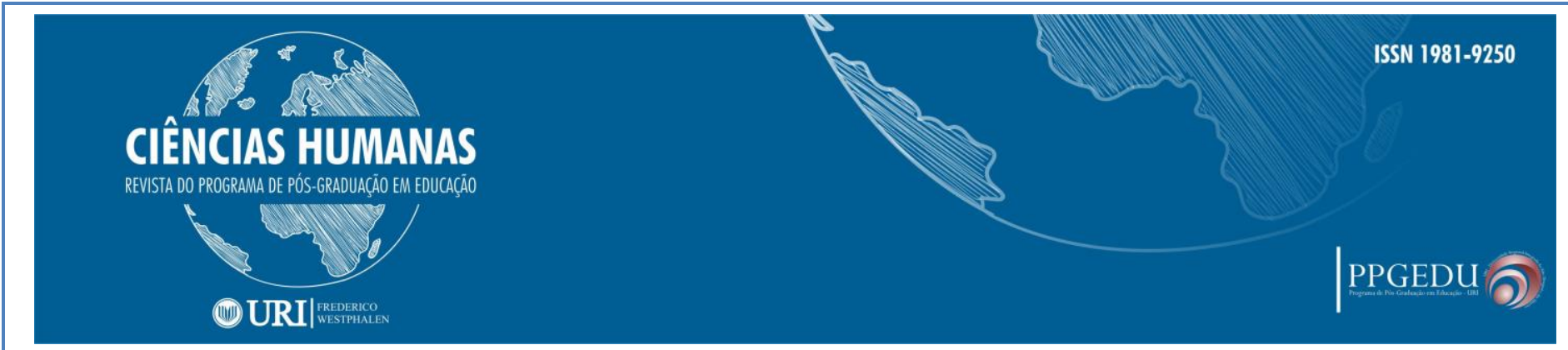

deve vir a ser acompanhada de uma autonomia docente crescente, calcada na competência em gerir a própria prática educativa; pois a profisssão envolve o "ensinareducando" que não se resume ao domínio de "habilidades e conhecimentos", a aplicação de regras ou a receitas de como ensinar (GATTI, 2010). Espera-se, do perfil do professor, além de competências muito amplas, um percurso de desenvolvimento pessoal que extrapole o currículo e os conhecimentos teórico-práticos da formação inicial e continuada, atribuindo ao professor a busca pessoal do seu desenvolvimento e da sua profissão.

\section{CONSIDERAÇÕES FINAIS}

Ao partirmos de uma análise sobre as exigências mínimas de formação de professores em Portugal e no Brasil, debruçamo-nos sobre os preceitos legais que apontam para uma exigência crescente de profissionalização dos professores. Mais que a exigência de formação em nível superior, a profissão exige o domínio teórico das áreas de conhecimento que fundamentam a educação, das áreas de ensino, dos métodos e das tecnologias educacionais. No Brasil, como em Portugal, essas exigências recaem sobre a qualificação a nível superior com uma carga horária mínima de formação, o direcionamento de conteúdos mínimos e um perfil profissional repleto de competências almejadas para esses profissionais. Assim, "a profissionalização dos professores está dependente da possibilidade de construir um saber pedagógico que não seja puramente instrumental" (NÓVOA, 1999, p.15).

Mas é justamente ao analisarmos mais de perto o perfil profissional que nos deparamos com a ideia de um superprofissional, o que nos faz retomar, inclusive, os primórdios da profissão vista como uma abdicação da vida pessoal em detrimento de uma missão ou da vocação de ensinar. Dominar os conteúdos de área, ser questionador e crítico, atentar ao currículo nacional, ter sensibilidade aos problemas sociais e ser equilibrado emocionalmente para lidar com os dilemas que se apresentam diuturnamente ao exercício da docência; não nos parece mesmo capaz de caber no projeto pedagógico ou na grade curricular de um curso inicial de formação dos professores. A despeito das condições de trabalho, do plano de carreira, da valorização da profissão, das demandas sociais que se acumulam na porta da escola, será o professor capaz de assumir profissional e pessoalmente este perfil?

Vislumbramos, portanto, uma profissionalização que não se encerra na técnica, nem no domínio de um conjunto de conhecimentos da área, porque a docência é uma profissão de cunho social, “(...) compreendida como uma forma particular de trabalho sobre o humano, ou seja, uma atividade em que o trabalhador se dedica ao seu 'objeto' 


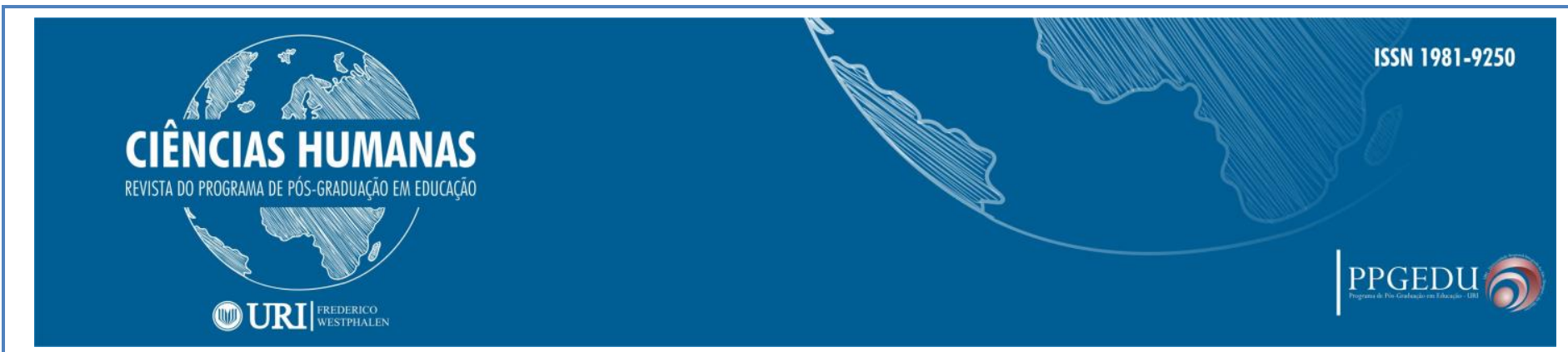

de trabalho que é justamente um outro ser humano, no modo fundamental de interação humana" (TARDIF e LESSARD, 2005, p. 08).

Formar professores tem sido um grande desafio, não somente nos países aqui citados, um desafio que não se encerra nas exigências formativas, nem mesmo na valorização da profissão, mas na compreensão da profissão. Concordamos com Tardif e Lessard (2005, p. 49-51) quando afirmam que o trabalho docente pode ser analisado como um trabalho socializado, compreendendo três dimensões: (1) as atividades docentes propriamente ditas, que envolvem a interação inerente às estratégias, aos recursos, aos saberes e ao ambiente organizacional; (2) o status, que remete a identidade do professor, tanto na organização quanto socialmente; e (3) a experiência, que é o modo como é vivenciado e significado pelo docente.

Não obstante as diferenças que separam Portugal e Brasil, a formação dos professores expressa nos dois países parece revelar a expectativa de que cada professor se aproprie de sua experiência, de sua prática e se disponha a um processo de desenvolvimento (pessoal e profissional) que promova o seu saber (fazer e estar) na profissão. Resta saber se estas exigências são passíveis de realização no âmbito da formação inicial, que se quer estritamente mais técnica em Portugal ou mais aberta as demandas sociais, como no Brasil, ou se as mesmas se perderão na retórica das reformas que permanecem, aqui como além mar, no papel. Tal aproximação da realidade da formação inicial se faz necessária, ainda que não seja o objetivo desta incursão, assim como a compreensão de como os professores se apropriam desse mandato e de que forma lhe estarão a dar cumprimento.

Ao concluirmos esta análise inicial sobre a formação dos professores em Portugal e no Brasil, afirmamos que a discussão não se encerra na legislação, mas no aprofundamento da compreesão do modo como efetivamente formam-se os professores e de como estes assumem as expectativas sobre si e sua profissão. Far-se-á necessária uma incursão sobre as trajetórias pessoais, as práticas docentes e a construção da profissionalidade, que não se resume à formação em si mesma, mas ao modo como a própria profissão é significada pelo professor e pela pessoa que é o professor.

\section{REFERÊNCIAS}

BRASIL. Lei de Diretrizes e Bases da Educação Nacional. Lei número 9394, 20 de dezembro de 1996. Diário Oficial [da] República Federativa do Brasil, Poder Executivo, Brasília, DF, 23 dez. 1996. P. 27833. Disponível em http://www.planalto.gov.br/ccivil_03/leis/L9394.htm Acesso em 24 set. 2018. 
BRASIL. Diretrizes Curriculares Nacionais para a formação inicial em nível superior. Resolução número 2, 01 de julho de 2015. Diário Oficial da União, Brasília, 2 de julho de 2015 - Seção 1 - pp. 8-12. Disponível em:

http://portal.mec.gov.br/index.php?option=com_docman\&view=download\&alias $=1771$ 9-res-cne-cp-002-03072015\&category_slug=julho-2015-pdf\&Itemid=30192 Acesso em 24 set. 2018.

Conselho Nacional de Educação. Formação Inicial de Professores [Textos do Seminário realizado na Universidade do Algarve a 29 de abril de 2015] Coleção: Seminários e Colóquios. Algarve, Portugal. Edição Eletrónica: novembro de 2015 ISBN: 978-972-8360-94-8 Disponível em http://www.cnedu.pt/content/edicoes/seminarios_e_coloquios/LivroCNE_FormacaoInic ialProfessores_10dezembro2015.pdf Acesso em 07 de agosto de 2018.

Direção-Geral do Ensino Superior (DGES). Guia de Candidatura desenvolvido pela Direção Geral do Ensino Superior de Portugal, S/D. Disponível em: http://www.dges.gov.pt/guias/indcurso.asp?curso=9853 Acesso em 18 set. 2018.

GATTI, Bernadete. Formação de professores no Brasil: características e problemas. Revista Educação e Sociedade: Campinas, v. 31, n. 113, p. 1355-1379, out.-dez. 2010. Disponível em: http://www.scielo.br/pdf/es/v31n113/16.pdf Acesso em 25 set. 2018.

Instituto Nacional de Estudos e Pesquisas Educacionais Anísio Teixeira. Indicadores educacionais elaborados pelo INEP, 2017. Disponível em:

http://portal.inep.gov.br/web/guest/indicadores-educacionais Acesso em 18 set. 2018.

LIBÂNEO, José Carlos. A aprendizagem escolar e a formação de professores na perspectiva da psicologia histórico-cultural e da teoria da atividade. Revista Educar, Curitiba, n. 24, p. 113-147, 2004. Editora UFPR.

MOREIRA, Plínio Cavalcanti. (2012). 3+1 e suas (In)Variantes (Reflexões sobre as possibilidades de uma nova estrutura curricular na Licenciatura em Matemática).

Bolema: Boletim de Educação Matemática, 26(44), p.1137-1150, 2012.

https://dx.doi.org/10.1590/S0103-636X2012000400003

NÓVOA, António. Os professores e a sua formação. Lisboa: Dom Quixote. ISBN 972-20-1008-5. p. 13-33, 1992. Disponível em: http://hdl.handle.net/10451/4758 Acesso em 10 set. 2017.

NOVOA, António. Os professores na virada do milênio: do excesso dos discursos à pobreza das práticas. Educação e Pesquisa. [online]. vol.25, n.1, pp.11-20, Junho 1999. Disponível em: http://dx.doi.org/10.1590/S1517-97021999000100002 Acesso em 25. set. 2018. 
PORTUGAL. Lei de Bases do Sistema Educativo. Lei número 46, 14 de outubro de 1986. Disponível em: https://dre.pt/application/conteudo/222418 Acesso em 24 set. 2018.

PORTUGAL. O perfil geral de desempenho profissional do educador de infância e dos professores dos ensinos básico e secundário. Decreto-Lei número 240, 30 de Agosto de 2001. Disponível em: https://dre.pt/application/conteudo/631837 Acesso em 24 set. 2018.

PORTUGAL. Aprova os perfis específicos de desempenho profissional do educador de infância e do professor do 1. $^{\circ}$ ciclo do ensino básico. Decreto-Lei número 241, 30 de Agosto de 2001. Disponível em:

https://www.dge.mec.pt/sites/default/files/Basico/dl241_01.pdf Acesso em 24 set. 2018.

PORTUGAL. Regime jurídico da habilitação profissional para a docência na educação pré-escolar e nos ensinos básico e secundário. Decreto-Lei número 43, 22 de Fevereiro de 2007. Diário da República, 1.a série - N.o 38 - 22 de Fevereiro de 2007. Disponível em: https://dre.pt/application/conteudo/517819 Acesso em 18 set. 2018.

SAVIANI, Dermeval. Formação de professores: aspectos históricos e teóricos do problema no contexto brasileiro. Revista Brasileira de Educação. V. 14 n. 40 jan./abr. 2009. Disponível em: http://www.scielo.br/pdf/rbedu/v14n40/v14n40a12.pdf Acesso em 24 set. 2018.

TARDIF, Maurice. ; LESSARD, Claude. O trabalho docente: elementos para uma teoria da docência como profissão de interações humanas. Petrópolis, RJ: Vozes, 2005.

UNESCO. Educação: um tesouro a descobrir; Relatório para a UNESCO da Comissão Internacional sobre a Educação para o século XXI. Brasília: Unesco, 2010. Disponível em: http://unesdoc.unesco.org/images/0010/001095/109590por.pdf Acesso em 24 de set. 2018. 